\title{
A Protein from the Mold Aspergillus giganteus Is a Potent Inhibitor of Fungal Plant Pathogens
}

\author{
L. Vila, ${ }^{1}$ V. Lacadena, ${ }^{2}$ P. Fontanet, ${ }^{1}$ A. Martinez del Pozo, ${ }^{2}$ and B. San Segundo ${ }^{1}$ \\ ${ }^{1}$ Departamento de Genética Molecular, Instituto de Biología Molecular de Barcelona, CID-CSIC, Jordi \\ Girona 18, 08034 Barcelona, Spain; '2Departamento de Bioquímica y Biología Molecular, Facultad de \\ Química, Universidad Complutense, 28040 Madrid, Spain \\ Submitted 15 March 2001; Accepted 18 July 2001.
}

\begin{abstract}
A purified preparation of antifungal protein (AFP) from Aspergillus giganteus exhibited potent antifungal activity against the phytopathogenic fungi Magnaporthe grisea and Fusarium moniliforme, as well as the oomycete pathogen Phytophthora infestans. Under conditions of total inhibition of fungal growth, no toxicity of AFP toward rice protoplasts was observed. Additionally, application of AFP on rice plants completely inhibited $M$. grisea growth. These results are discussed in relation to the potential of the afp gene to enhance crop protection against fungal pathogens in transgenic plants.
\end{abstract}

Additional keywords: Oryza sativa, Pyricularia grisea.

The mold Aspergillus giganteus, isolated from the soil of a farm in Michigan (U.S.A.), has been reported to produce a basic, small-sized (51 amino acids) protein showing antifungal properties, the antifungal protein (AFP) protein (Nakaya et al. 1990; Olson and Goerner 1965). This AFP has been thoroughly characterized from the structural point of view (Campos-Olivas et al. 1995; Lacadena et al. 1995). Essentially, the AFP structure is a highly twisted $\beta$-barrel stabilized by four internal disulfide bridges. In this regard, it resembles some other antifungal polypeptides found in plants, such as defensins or thionins (Bruix et al. 1993; Garcia-Olmedo et al. 1998). Production of some other proteins that show high sequence homology with the A. giganteus AFP have been described in other fungi, such as A. niger and Penicillium chrysogenum (Gun Lee et al. 1999; Marx et al. 1995). Presumably, the production of such antimicrobial proteins would provide the producer with a competitive advantage in the environment.

We are interested in studying the antifungal properties of compounds that are produced as part of the defense response of different organisms against phytopathogens, as well as in their application for the development of fungus-resistant plants through gene transfer. Toward this end, we previously reported the ability of cecropin A-derived peptides to inhibit the growth of several fungal plant pathogens (Cavallarin et al. 1998). Previous studies indicated that AFP inhibited the growth of some filamentous fungi, whereas no effect was observed against yeasts or bacteria (Lacadena et al. 1995). In this work, we in-

Corresponding author: Blanca San Segundo;

E-mail: bssgmb@cid.csic.es vestigated the antifungal properties of the Aspergillus AFP protein against various economically important fungal pathogens, namely Magnaporthe grisea and Fusarium moniliforme and the oomycete Phytophthora infestans. The fungus $M$. grisea (anamorph Pyricularia grisea) was chosen because this fungus causes rice blast, the most important fungal disease of cultivated rice (Oryza sativa L.) due to its widespread distribution and destructiveness (Ou 1985; Sun and Snyder 1981). $M$ grisea is also a pathogen of a large number of cereals and grasses. A continuous effort is being made to control this disease, mainly by using fungicides and breeding cultivars resistant to the disease. Breeding of durable resistance to this fungus is, however, a difficult problem, not only because of the high degree of pathogenic variability of $M$. grisea but also because of the large number of fungal races encountered in the field population.

The fungus $F$. moniliforme causes diseases in a wide range of crops, such as seedling blight and damping-off in maize and rice (Agrios 1988). In maize, it is also responsible for stalk and ear rots (McGee 1988). Additionally, F. moniliforme produces significant quantities of the toxin moniliformin, which adversely affects human and animal health (Marasas et al. 1984). Finally, P. infestans causes the late blight disease of potato, a disease that is found in nearly all areas of the world in which potatoes are grown (Agrios 1988). Late blight disease is also very destructive to tomatoes and to several other species in the family Solanaceae. Consequently, finding specific compounds exhibiting antifungal properties against M. grisea, $F$. moniliforme, and $P$. infestans is a requisite for creating varieties with improved resistance to these pathogens.

In this study, we determined the antifungal activity of AFP against phytopathogenic fungi using a microtiter plate assay (Cavallarin et al. 1998). For this, AFP was purified from the extracellular medium of A. giganteus MDP18894 cultures (Martinez-Ruiz et al. 1997). Homogeneity of the protein preparation was confirmed by sodium dodecyl sulfate-polyacrylamide gel electrophoresis and amino acid composition analysis, as well as by its spectroscopical features (Lacadena et al. 1995). The concentrations required for 50\% growth inhibition (inhibitory concentrations $\left[\mathrm{IC}_{50} \mathrm{~s}\right]$ ) and for total inhibition of fungal growth (MICs) were taken as a measure of the inhibitory potency of AFP on a given fungus (Fig. 1). After $24 \mathrm{~h}$ of incubation, as little as $50 \mathrm{nM}$ AFP was sufficient for $50 \%$ growth inhibition of M. grisea (Fig. 1A). M. salvinii (Scle- 

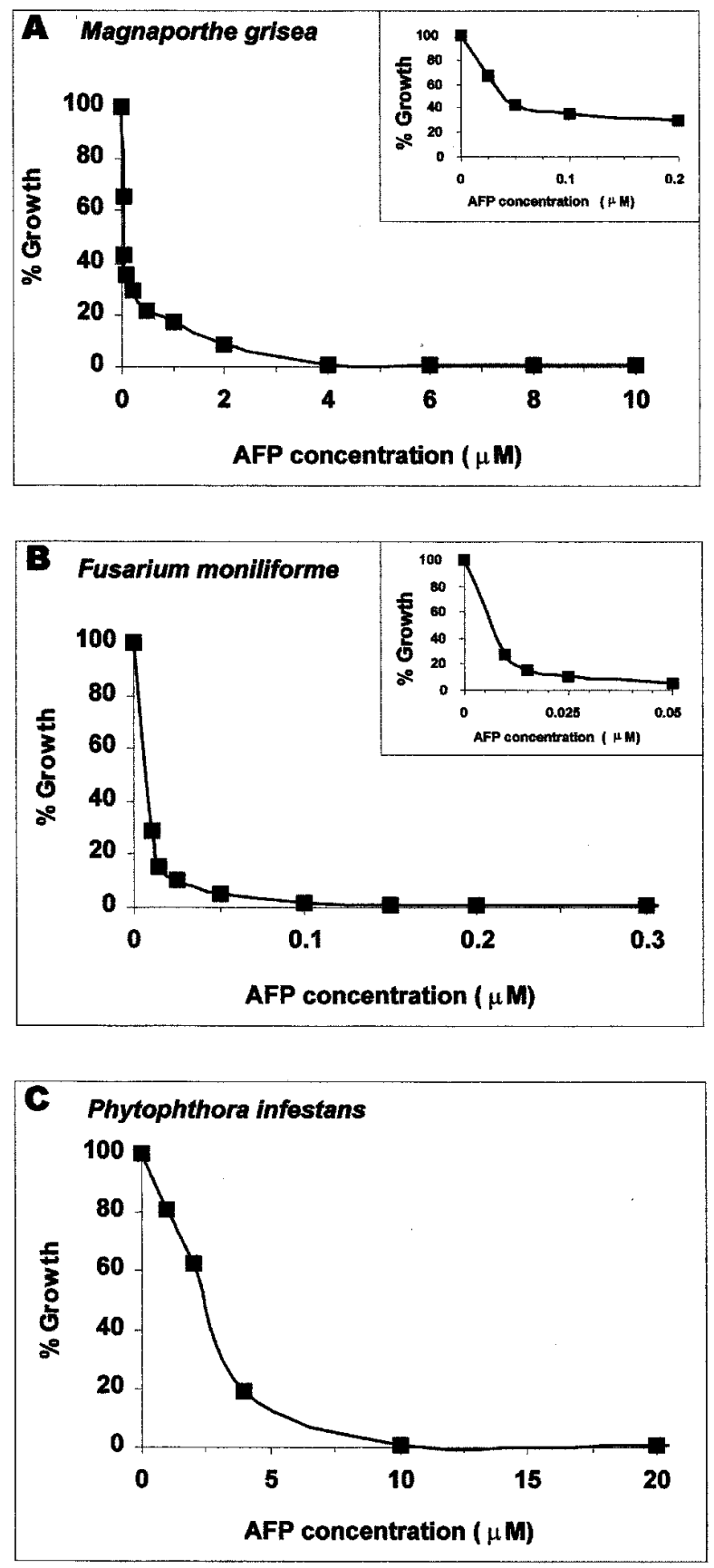

Fig. 1. In vitro antifungal activities of antifungal protein (AFP). Inhibition curves of A, Magnaporthe grisea; B, Fusarium moniliforme; and C, Phytophthora infestans. Tests were performed in potato dextrose broth (PDB) medium in 96-well microtiter plates (Cavallarin et al. 1998). Spore suspensions at concentrations of $1 \times 10^{5}$ spores per $\mathrm{ml}($. moniliforme $)$ or $1 \times$ $10^{6}$ spores per $\mathrm{ml}$ (M. grisea and P. infestans) were pipetted onto PDB medium and allowed to germinate for $6 \mathrm{~h}$ at 26 to $28^{\circ} \mathrm{C}$ (F. moniliforme and M. grisea $)$ or $18^{\circ} \mathrm{C}$ (P. infestans) in the darkness, and the absorbance at 595 $\mathrm{nm}$ was determined. Purified AFP solutions were added to the pregerminated spores to the desired final concentrations. Fungal growth is expressed as percentage of the growth of control cultures (100\% growth represents fungal growth in PDB medium without AFP). Peptide concentrations required for $50 \%$ growth inhibition $\left(\mathrm{IC}_{50}\right)$ and total inhibition of fungal growth (MIC), after $24 \mathrm{~h}$ of incubation with AFP, were determined from the dose response curves. Three repeats of each bioassay were performed for each of three different preparations of spore suspensions. rotium oryzae) was similarly inhibited by AFP (data not shown). F. moniliforme was particularly sensitive to AFP. In this case, as little as $7 \mathrm{nM}$ was sufficient for $50 \%$ growth inhibition (Fig. 1B). This antifungal assay was extended to other $\mathrm{Fu}$ sarium spp. that are known to be pathogens of different crops, such as $F$. proliferatum, $F$. oxysporum f. sp. radicis lycopersici, and $F$. lateritium, as well as to the fungus Microdochium nivale (previously named $F$. nivale). The $\mathrm{IC}_{50} \mathrm{~s}$ found for these fungi were within the range of 10 to $100 \mathrm{nM}$. Finally, AFP was also active against $P$. infestans, although its antifungal potency against this pathogen was lower than in the cases of $M$. grisea and $F$. moniliforme ( $\mathrm{IC}_{50}$ of $2.5 \mu \mathrm{M}$, Fig. $\left.1 \mathrm{C}\right)$. The MICs found for the inhibition of $M$. grisea, F. moniliforme, and $P$. infestans were $4 \mu \mathrm{M}, 100 \mathrm{nM}$, and $10 \mu \mathrm{M}$, respectively.

Furthermore, preincubation of AFP with the anti-AFP antiserum, but not with nonimmune serum, resulted in loss of its inhibitory potency, indicating that AFP was the primary agent that caused the inhibition of fungal growth (data not shown). Western blot analyses of fungal cultures containing AFP revealed that AFP remained stable in the in vitro bioassay after $48 \mathrm{~h}$ of incubation (data not shown). Finally, AFP biotoxicity was not abolished when the protein was preincubated either with proteinase $\mathrm{K}(100 \mu \mathrm{g} / \mathrm{ml})$ or with dithiothreitol $(2.5 \mathrm{mM}, 2 \mathrm{~h}$ at $\left.37^{\circ} \mathrm{C}\right)$ or was subjected to heat treatment $\left(100^{\circ} \mathrm{C}\right.$ for $\left.10 \mathrm{~min}\right)$ prior to its use in the in vitro antifungal assays (data not shown). The remarkable stability and resistance to proteolysis of AFP has been previously reported (Lacadena et al. 1995).

Fungal growth inhibition mediated by AFP was also analyzed microscopically (Fig. 2). M. grisea grown in the presence of AFP showed short, thick, and highly septated hyphae with constricted apical regions extruding from condensed mycelial aggregates compared with the buffer control with a much-more-extended mycelium with long and thin hyphae (Fig. 2A to D). The morphology of F. moniliforme hyphae was similarly changed (Fig. 2E to H). P. infestans hyphae also showed a marked alteration in their morphology. In addition to branch disruption, the most dramatic effects of AFP on $P$. infestans growth was the promotion of sporangia formation (Fig. 2I to L).

To summarize, AFP displayed potent antifungal activity against the pathogens $M$. grisea, $F$. moniliforme, and $P$. infestans. Differences in susceptibility of the phytopathogens here assayed to AFP were, however, observed. Low nanomolar concentrations of AFP inhibit growth of M. grisea and F. moniliforme, whereas low micromolar concentrations of AFP are needed for growth inhibition of $P$. infestans. The $\mathrm{IC}_{50} \mathrm{~s}$ found for the inhibition of fungal growth by AFP are significantly lower than those reported for plant antifungal proteins and peptides previously described (defensins and thionins). Morphological effects associated to the inhibition of fungal growth by AFP and disruption of mycelial growth, as well as promotion of sporangia formation ( $P$. infestans), were observed. The mechanism by which AFP exerts its antifungal activity is, however, unknown.

Another aim of this study was to estimate the toxicity of AFP on rice protoplasts. Toward this end, protoplasts were prepared from the commercial rice variety Senia and then incubated with AFP at concentrations lethal to fungi $(1,5$, or $10 \mu \mathrm{M}$ AFP). The viability of rice cells was not affected, as judged by fluorescein diacetate staining (Table 1). Since the $\mathrm{IC}_{50} \mathrm{~S}$ of AFP against rice-pathogenic fungi were found in the low 
nanomolar range, there is a wide range of concentrations at which AFP would kill intruding fungi with no harm to the plant cells.

To assess the effectiveness of AFP in planta, leaves of rice plants were locally inoculated with a suspension of $M$. grisea spores to gave rise to a macroscopically visible plant reaction. Twenty-four hours after inoculation, the infected leaf areas were treated, or not (control plants), with AFP. No apparent symptoms developed in fungus-infected leaves that had been treated with AFP. In leaves that had not been treated with AFP, however, a significant number of blast lesions were observed 5 days postinoculation with $M$. grisea (Fig. 3A and B).

Finally, protection afforded by AFP was also assayed by spraying rice plants with $M$. grisea spore suspensions. Development of disease symptoms was monitored visually both in inoculated plants (control plants) and in plants that had been inoculated and treated with AFP. Control plants developed
Table 1. Viability of rice protoplasts in the presence of antifungal protein $(\mathrm{AFP})^{\mathrm{a}}$

\begin{tabular}{lc}
\hline AFP & Viability of rice protoplasts $(\%)$ \\
\hline No AFP & 100 \\
$1 \mu \mathrm{M}$ & 91 \\
$5 \mu \mathrm{M}$ & 98 \\
$10 \mu \mathrm{M}$ & 96 \\
M.D. & 45 \\
\hline
\end{tabular}

a Protoplasts were prepared from calli of the japonica rice (Oryza sativa) cv. Senia by overnight $(18 \mathrm{~h})$ enzyme digestion following the protocol described by Nagy and Maliga (1976). Protoplast density was adjusted to $1.6 \times$ $10^{6}$ protoplasts per ml per tube, and the AFP was slowly added to the protoplast suspension to the desired final concentration $(1,5$, or $10 \mu \mathrm{M}$ AFP). Protoplasts were incubated with AFP at $28^{\circ} \mathrm{C}$ in the dark for $24 \mathrm{~h}$. Viability of rice protoplasts was determined by staining with fluorescein diacetate (FDA) (Power and Chapman 1985). Controls with no AFP or with protoplasts that had been mechanically damaged (M.D.) by vigorous pipetting, frozen, and then subjected to FDA staining were also carried out. Usually, three measurements were performed per treatment and per concentration.

\section{+ AFP}
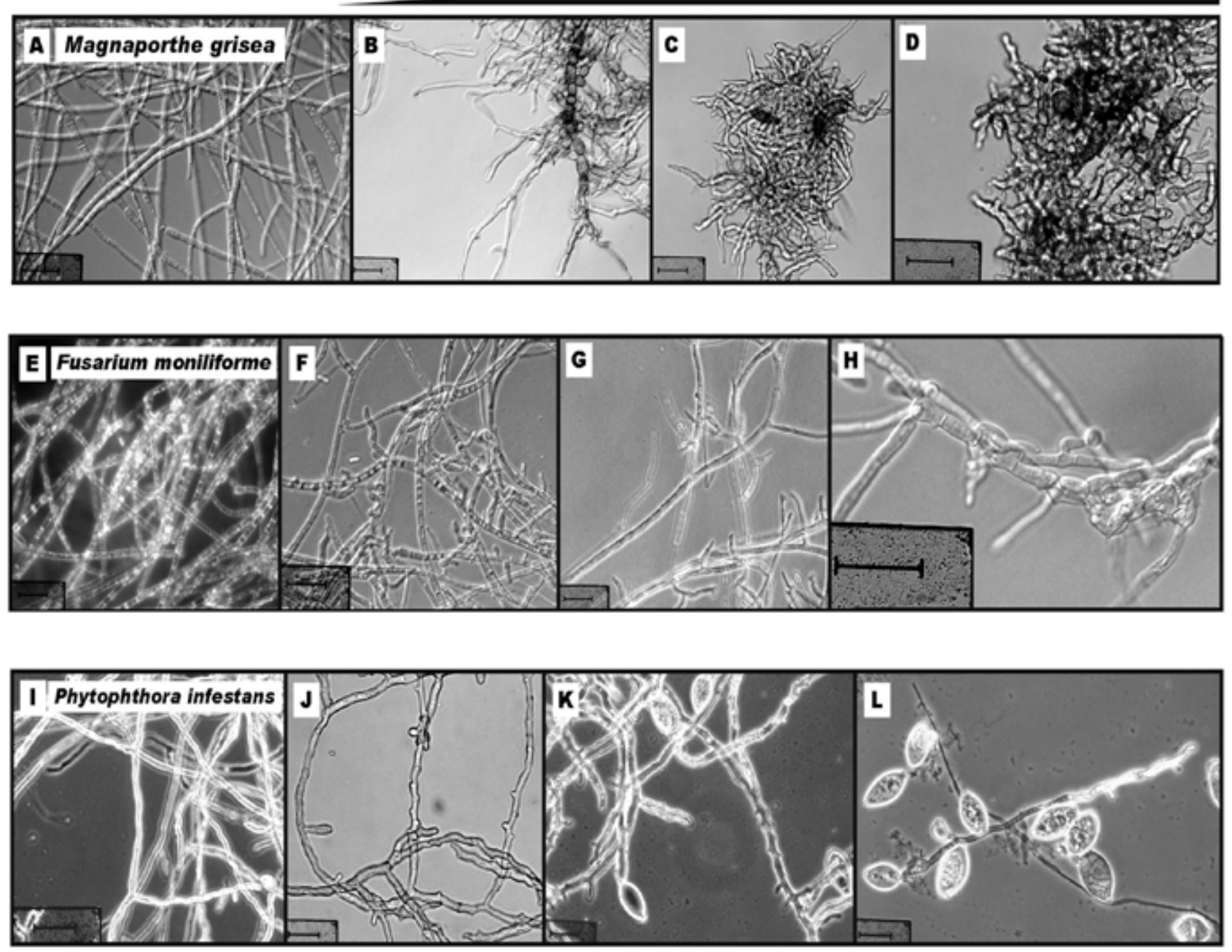

Fig. 2. Morphological changes induced in Magnaporthe grisea, Fusarium moniliforme, and Phytophthora infestans after exposure to the Aspergillus antifungal protein (AFP). M. grisea grown A, in potato dextrose broth (PDB) medium or in the presence of AFP at concentrations of $\mathbf{B}, 25 \mathrm{nM} ; \mathbf{C}, 100 \mathrm{nM}$; and $\mathbf{D ,} 500 \mathrm{nM}$. F. moniliforme grown $\mathbf{E}$, in PDB medium or in the presence of AFP at concentrations of $\mathbf{F}, 50 \mathrm{nM} ; \mathbf{G}, 300 \mathrm{nM}$; and $\mathbf{H}, 1 \mu \mathrm{M}$. P. infestans grown I, in PDB medium or in the presence of AFP at concentrations of $\mathbf{J}, 100 \mathrm{nM} ; \mathbf{K}, 1 \mu \mathrm{M}$; and $\mathbf{L}, 10 \mu \mathrm{M}$. Micrographs were taken after $24 \mathrm{~h}$ of incubation of the different fungi with AFP. Bars $=40 \mu \mathrm{m}$. 
clear symptoms of infection that were observed at 7 days after inoculation with fungal spores, but they were absent in AFPtreated plants. About 6 weeks after inoculation with M. grisea spores, rice plants that were not treated with AFP died. On the contrary, lesions were absent in inoculated and AFP-treated plants (Fig. 3C).

To conclude, the high antifungal potency together with the protection here observed upon application of AFP on rice leaves, suggests that the afp gene may be a promising candidate for crop protection, and particularly for protection of cultivated rice varieties against $M$. grisea. The observation that AFP promotes sporangia formation of $P$. infestans suggests that the same strategies may also be useful to control diseases caused by this and related organisms. From a practical standpoint, however, the level of antifungal activity of a protein in transgenic plants would depend on rates of syn- thesis, secretion to the appropriate subcellular compartment (i.e., intercellular spaces and vacuoles), and degradation by plant proteolytic activities. In this regard, the stability of AFP and its resistance to proteolytic degradation makes it plausible to design protective strategies for expression of the AFP gene in transgenic plants through engineering the AFP sequence for targeting either vacuoles or secretion to the extracellular space. The use of a pathogen-inducible promoter leading to AFP synthesis shortly after infection could also be an efficient strategy to enhance resistance to fungal pathogens in crop plants. Alternatively, one can envision the direct application of AFP, either by surface application or by spraying, for the protection of plants against phytopathogenic fungi. Considering that AFP is a secreted protein, it offers an attractive and economical process for its rapid and convenient production.

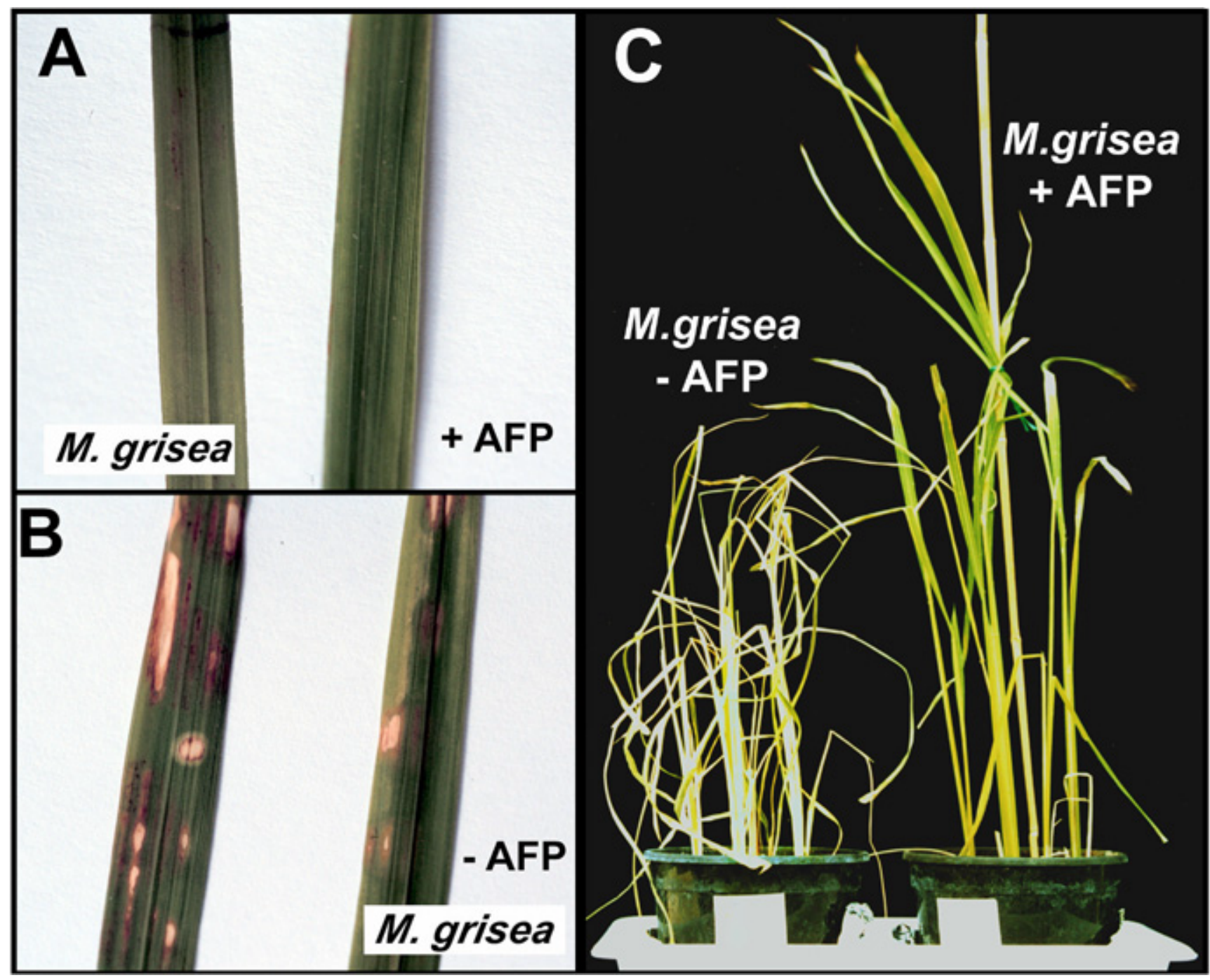

Fig. 3. Protection of rice plants against Magnaporthe grisea by direct application of antifungal protein (AFP). A and B, Rice leaves were locally infected with spores of $M$. grisea by droplet inoculations. For this, $20 \mu \mathrm{l}$ of spore suspension $\left(3.6 \times 10^{5}\right.$ spores per $\mathrm{ml}$ in $0.25 \%$ [vol/vol] Tween $20,0.5 \%$ $[\mathrm{wt} / \mathrm{vol}]$ gelatin) was applied onto leaf surfaces of rice plants. Twenty-four hours after inoculation with fungal spores, a drop of A, a 10- $\mu \mathrm{M}-\mathrm{AFP}$ solution or $\mathbf{B}$, sterile water was deposited at the same place as the infection drop. Pictures were taken 10 days after inoculation with fungal spores. C, Experiments to assess protection by AFP of $M$. grisea-infected rice plants were also carried out by spraying rice plants with AFP solutions. Plants at the fourleaf stage were sprayed with a spore suspension $\left(2.5 \times 10^{5}\right.$ spores per $\mathrm{ml}$, containing $0.02 \%$ [vol/vol] Tween 20) until leaves were covered with fine droplets. The plants were placed at 26 to $28^{\circ} \mathrm{C}$ for $24 \mathrm{~h}$ (16-h light/8-h dark) and then sprayed with water (left) or with an aqueous solution of AFP at a final concentration of $10 \mu \mathrm{M}$ (right). The photography was taken 6 weeks after infection. 


\section{ACKNOWLEDGMENTS}

We wish to thank D. Tharreau (CIRAD-Montpellier, France) and J. I. Ruiz de Galarreta (Centro Arkaute, Vitoria, Spain) for providing the Magnaporthe grisea (Pyricularia grisea, SP1) and Phytophthora infestans (strain 149/98) strains used in this study. L. Vila was a recipient of a predoctoral fellowship from the Centre de Refèrencia de Biotecnología (CERBA), Generalitat de Catalunya. This work was supported by grant $\mathrm{BIO} 2000-1682-\mathrm{C} 02-01$ from the Comisión Internacional de Ciencia y Tecnología to B. San Segundo.

\section{LITERATURE CITED}

Agrios, G. N. 1988. Plant Pathology. Academic Press, Inc., San Diego, CA, U.S.A

Bruix, M., Jimenez, M. A., Santoro, J., Gonzalez, C., Colilla, F. J., Mendez, E., and Rico, M. 1993. Solution structure of gamma 1-H and gamma 1-P thionins from barley and wheat endosperm determined by 1H-NMR: A structural motif common to toxic arthropod proteins. Biochemistry 32:715-724.

Campos-Olivas, R., Bruix, M., Santoro, J., Lacadena, J., Martinez del Pozo, A., Gavilanes, J. G., and Rico, M. 1995. NMR solution structure of the antifungal protein from Aspergillus giganteus: Evidence for cysteine pairing isomerism. Biochemistry 34:3009-3021.

Cavallarin, L., Andreu, D., and San Segundo, B. 1998. Cecropin Aderived peptides are potent inhibitors of fungal plant pathogens. Mol. Plant-Microbe Interact. 11:218-227.

Garcia-Olmedo, F., Molina, A., Alamillo, J. M., and RodriguezPalenzuela, P. 1998. Plant defense peptides. Biopolymers 47:479-491.

Gun Lee, D., Yub Shin, S., Maeng, C.-Y., Zhu Jin, Z., Lyong Kim, K., and Hahm, K.-S. 1999. Isolation and characterization of a novel antifungal peptide from Aspergillus niger. Biochem. Biophys. Res. Comm. 263:646-651.

Lacadena, J., Martinez del Pozo, A., Gasset, M., Patiño, B., CamposOliva, R., Vázquez, C., Martinez-Ruiz, A., Mancheno, J. M.,
Onaderra, M., and Gavilanes, J. G. 1995. Characterization of the antifungal protein secreted by the mould Aspergillus giganteus. Arch. Biochem. Biophys. 324:237-281.

Marasas, W. F. O., Nelson, P. E., and Toussoun, T. A. 1984. Toxigenic Fusarium species: Identity and Mycotoxicology. Pennsylvania State University Press, University Park, U.S.A.

Martinez-Ruiz, A., Martinez del Pozo, A., Lacadena, J., Mancheno, J. M., Oñaderra, M., and Gavilanes, J. G. 1997. Characterization of a natural larger form of the antifungal protein (AFP) from Aspergillus giganteus. Biochim. Biophys. Acta 1340:81-87.

Marx, F., Haas, H., Reindl, M., Stoffler, G., Lottspeich, F., and Redl, B. 1995. Cloning, structural organization and regulation of expression of the Penicillium chrysogenum paf gene encoding an abundantly secreted protein with antifungal activity. Gene 167:167-171.

McGee, D. C. 1988. Maize Diseases. A Reference Source for Seed Technologists. The American Phytopathological Society, St. Paul, MN, U.S.A.

Nagy, J. I., and Maliga, P. 1976. Callus induction and plant regeneration from mesophyll protoplasts of Nicotiana sylvestris. Z. Planzenphysiol. 78:453-458.

Nakaya, K., Omata, K., Okahashi, I., Nakamura, Y., Kolkenbrock, H., and Ulbrich, N. 1990. Amino acid sequence and disulfide bridges of an antifungal protein isolated from Aspergillus giganteus. Eur. J. Biochem. 193:31-38

Olson, B. H., and Goerner, G. L. 1965. $\alpha$-Sarcin, a new antitumour agent. I. Isolation, purification, chemical composition, and identity of a new amino acid. Appl. Microbiol. 13:314-321.

Ou, S. H. 1985. Rice Diseases, 2nd ed. Commonwealth Mycological Institute, Kew, England.

Power, J. B., and Chapman, J. V. 1985. Isolation, culture and genetic manipulation of plant protoplasts. Pages 37-65 in: Plant Cell Culture. A Practical Approach. R. A. Dixon, ed. IRL Press, Oxford.

Sun, S.-K., and Snyder, W. C. 1981. The bakanae disease of the rice plant. Pages 104-113 in: Fusarium: Diseases, Biology and Taxonomy. P. E. Nelson, T. A. Toussoun, and R. J. Cook, eds. Pennsylvania State University, University Park, U.S.A. 